\title{
RECIPROCAL CHANGES IN THE FIRING RATE OF NEOSTRIATAL AND DORSAL RAPHE NEURONS FOLLOWING LOCAL INFUSIONS OR SYSTEMIC INJECTIONS OF $D$-AMPHETAMINE: EVIDENCE FOR NEOSTRIATAL HETEROGENEITY ${ }^{1}$
}

\author{
GEORGE V. REBEC ${ }^{2}$ AND STEPHEN D. CURTIS \\ Department of Psychology, Indiana University, Bloomington, Indiana 47405
}

Received November 1, 1982; Revised March 17, 1983; Accepted May 10, 1983

\begin{abstract}
A local infusion of $d$-amphetamine ( $d$-AMPH) into the dorsal raphe nucleus (DRN) inhibited neuronal activity in this site and produced a mirror-image excitation in the ventrolateral, but not dorsomedial, neostriatum. This effect, which was mimicked by 5 -methoxy- $N, N$-dimethyltryptamine, a serotonin autoreceptor agonist, was not altered by pretreatment with $\alpha$-methyl-p-tyrosine. Similar regional differences in neostriatal activity were obtained following an electrolytic lesion of the DRN or an intraperitoneal injection of $d$-AMPH. In fact, whereas $1.0 \mathrm{mg} / \mathrm{kg}$ of $d$-AMPH accelerated ventrolateral activity and inhibited dorsomedial neurons, $7.5 \mathrm{mg} / \mathrm{kg}$ produced the opposite effect. At both doses, however, DRN activity was inversely related to firing rate in the ventrolateral, but not dorsomedial, neostriatum. These results indicate that only certain regions of the neostriatum are responsive to changes in DRN activity and that these regions respond differently to systemic injections of $d$-AMPH than other neostriatal sites.
\end{abstract}

The functional organization of the neostriatum has been the subject of intense anatomical, behavioral, and neurophysiological investigations (for reviews see Divac and Öberg, 1979; Kitai et al., 1979; Dray, 1980). Recently, these lines of research have produced evidence that this structure, long regarded as a homogeneous entity, is actually quite heterogeneous in terms of its afferent connections (Veening et al., 1980; Walaas, 1981; Carter, 1982; Kelley et al., 1982) its role in behavior (Neill et al., 1978; Divac and Diemer, 1980; Dunnett and Iversen, 1982), and its complex intrinsic neural connections (Mensah, 1977; Wilson and Groves, 1980; Chang et al., 1982). In fact, the distribution of neurotransmitters within the neostriatum suggests that this structure is divisible into compartments or zones that are neurochemically and pharmacologically distinct (Graybiel and Ragsdale, 1978; Pickel et al., 1980; Graybiel et al., 1981; Rea and Simon, 1981). Taken together, these data emphasize the need for a regional analysis of neostriatal function.

\footnotetext{
${ }^{1}$ This work was supported by United States Public Health Service Grant DA-02451-04 (G. V. R.). We wish to thank Doris Harris, Suzanne Hull, Josephine Centore, and Kenneth Zimmerman for expert assistance. Smith, Kline \& French Laboratories provided a generous supply of $d$-amphetamine sulfate.

${ }^{2}$ To whom correspondence should be addressed.
}

In this report, we focused on the role of the dorsal raphe nucleus (DRN) in controlling neostriatal activity. We have previously shown that a local infusion of $d$ amphetamine ( $d$-AMPH) directly into the DRN inhibits impulse flow in this site presumably by releasing endogenous serotonin (5-HT) from dendritic terminals or recurrent axon collaterals onto inhibitory autoreceptors (Rebec et al., 1982). 'These results are consistent with the view that 5 -HT-containing neurons can regulate their own firing rate by a process of self-inhibition (Mosko and Jacobs, 1977; Wang and Aghajanian, 1977, 1982). Inhibition of activity in the DRN, however, may not exert uniform effects in the neostriatum since DRN afferents have been identified mainly in the ventral and lateral portions of this structure (Conrad et al., 1974; Ternaux et al., 1977; Azmitia and Segal, 1978; Van Der Kooy,1979; Steinbusch, 1981). It is conceivable, therefore, that those sites receiving DRN input comprise separate and functionally independent areas of the neostriatum. To test this hypothesis and to shed additional light on the functional organization of the neostriatum, we recorded neuronal activity simultaneously in the DRN and in specific neostriatal regions following local manipulations of DRN activity. We also extended our work with systemic $d$-AMPH to record the dose-dependent effects of this drug both in the dorsomedial neostriatum, which had been the site of our previous recordings 
(Rebec and Segal, 1978; Rebec and Zimmerman, 1980; Rebec et al., 1981; Alloway and Rebec, 1983), and in those regions that receive DRN input. Our results not only support the notion of neostriatal heterogeneity, they also suggest that changes in impulse flow in the DRN may mediate, in part, regional differences in the response to $d$-AMPH and related psychoactive drugs.

\section{Materials and Methods}

Data were obtained from approximately 150 male Sprague-Dawley rats (Harlan Sprague-Dawley, Inc., Indianapolis, IN) weighing between 350 and $450 \mathrm{gm}$ at the time of experimentation. Each animal, secured in a stereotaxic instrument under ether anesthesia, was prepared for single unit recordings.

Surgery. Holes were drilled in the skull overlying the neostriatum (approximately 6.5 to $8.5 \mathrm{~mm}$ anterior and 2.0 to $3.5 \mathrm{~mm}$ lateral to stereotaxic zero) and DRN (approximately 0.1 to $0.5 \mathrm{~mm}$ anterior and $0.0 \mathrm{~mm}$ lateral to stereotaxic zero) according to the coordinates of König and Klippel (1963). Local anesthetics (procaine and Xylocaine) were applied to all points of surgical and stereotaxic contact. The ether was withdrawn and the animals were immobilized with an intraperitoneal injection of $2.5 \mathrm{mg} / \mathrm{kg}$ of $d$-tubocurarine chloride (Eli Lilly and Co., Indianapolis, IN). Positive pressure artificial respiration (Harvard Instruments rodent respirator), which was maintained by a rubber cone fitted snugly over the snout, was adjusted to maintain a level of carbon dioxide at $4.0( \pm 0.5) \%$ of expired air (Beckman medical gas analyzer). Heart rate and body temperature $\left(37 \pm 0.5^{\circ} \mathrm{C}\right)$ were also monitored throughout each experiment. Local anesthetic was administered at periodic intervals and commercial eyedrops were applicd to prevent corneal drying. Previous recordings of electrocorticographic activity have been dominated by large, slow waves indicating effective local anesthesia (Rebec et al., 1979). General anesthetics were avoided during the recording session because of their inhibitory effects on neostriatal activity (e.g., Bloom et al., 1965; Rocha-Miranda, 1965; Feltz and Albe-Fessard, 1972; Zarecki et al., 1976). Some "silent" neostriatal cells in animals under general anesthesia can be activated by electrical stimulation or by iontophoretic application of excitatory amino acids. Such cells, however, are not representative of the majority of neostriatal neurons (see Connor, 1975). Moreover, excessive application of excitatory substances can lead to depolarization block or, at the very least, can produce an artificial background level of firing. It is especially difficult to construct meaningful dose-response relationships under such circumstances. General anesthetics have also been reported to interfere with the action of psychoactive drugs in the DRN (Trulson and Trulson, 1983).

Single unit recording. Tungsten microelectrodes, having impedances of 2.0 to 6.0 megohms, were used to record single unit discharges which were amplified and displayed by conventional means. Neuronal firing rate was counted on a minute-by-minute basis using a high speed printer-counter (Digitec) in conjunction with a neuronal spike analyzer (Mentor). Window discriminators were set to record the activity of a single neuron isolated to a signal-to-noise ratio of 3:1 or more. Spon- taneous discharges were recorded for at least $30 \mathrm{~min}$ before an experimental drug injection in order to ensure a stable base line firing rate. The mean spontaneous firing rate per minute was calculated for the $10-\mathrm{min}$ period immediately preceding the drug injection and was defined, in each case, as $100 \%$. Drug-induced changes in firing rate were expressed as a percentage of the $100 \%$ base line rate. This procedure allowed for comparisons of group data despite individual differences in base line firing rates. For descriptive purposes, a decrease or increase in firing rate following drug administration was defined as a change of $40 \%$ from the pre-injection base line rate for a period of $10 \mathrm{~min}$ or longer (spontaneous predrug fluctuations in activity never reached this criterion). Unit activity that failed to maintain a constant signal-to-noise ratio and did not return to within $\pm 40 \%$ of the pre-injection rate for at least $10 \mathrm{~min}$ was not included in the data.

Recordings in the DRN were characteristic of those previously described for 5-HT-containing neurons (Gallager and Aghajanian, 1976; Wang and Aghajanian, 1982). Thus, slow (30 to 150 spikes/min), regular, spontaneously active discharges having an initial positive deflection of long duration were routinely recorded in the DRN. Firing patterns typically assigned to non-5-HT neurons, including "silent" neurons or neurons with a high spontaneous rate (greater than 400 spikes/min), were rare and were not included in the data. Neurons throughout the neostriatum were characterized by a slow and somewhat variable firing pattern that has been described in previous reports (Rebec and Segal, 1978; Rebec et al., 1981). Impulses recorded from neostriatal neurons, for example, had a magnitude of 150 to $300 \mu \mathrm{V}$ and a spontaneous rate of between 20 and 250 spikes $/ \mathrm{min}$. Photographic records of DRN and neostriatal unit activity, representative of recordings in the present study, have appeared elsewhere (Rebec and Groves, 1975; Rebec et al., 1982).

Infusion studies. A stainless steel infusion cannula (30 gauge) was lowered at a $10^{\circ}$ angle into the DRN to within $500 \mu \mathrm{m}$ of the tungsten recording electrode. Unit activity was recorded simultaneously in the DRN and neostriatum as described above. In some cases, simultaneous recordings were obtained in different regions of the neostriatum while $d$-AMPH was infused into the DRN. The infusion cannula was connected to a programmable infusion pump which operated at an infusion rate of 1.2 $\mu \mathrm{l} / \mathrm{hr}$. Saline or $d$-AMPH sulfate (free base), ranging in concentration from $1 \times 10^{-6}$ to $2 \times 10^{-4} \mathrm{M}$, was infused into the DRN for periods of from 6 to $9 \mathrm{~min}$. The effective concentration of $d$-AMPH was determined in preliminary experiments that produced a response in the DRN comparable to that observed following an intraperitoneal injection of $1.0 \mathrm{mg} / \mathrm{kg}$ of $d$-AMPH (see below). Furthermore, the concentration was the same as that which produced similar changes in the activity of dopaminergic neurons in the substantia nigra following a direct infusion into this site (Groves et al., 1975). Approximately 3 $\mathrm{hr}$ before the $d$-AMPH infusion, some animals received an intraperitoneal injection of $250 \mathrm{mg} / \mathrm{kg}$ of $\alpha$-methyl- $p$ tyrosine ( $\alpha$-MT) methyl ester (Sigma Chemical Co., St. Louis, MO). In the DRN of a separate group of animals, 
normal saline was infused at the same rate and for the same period of time as $d$-AMPH to control for any mechanical artifacts that may accompany the infusion procedure.

Lesion studies. Recording electrodes were lowered into the neostriatum and DRN as described above. Following the isolation of single unit discharges in both sites, current $(5 \mathrm{~mA})$ was passed through the DRN electrode for $15 \mathrm{~min}$ to produce an electrolytic lesion of the entire structure. Changes in neuronal activity were then recorded in the neostriatum for a minimum of $60 \mathrm{~min}$.

Systemic d-AMPH. Following the isolation of single unit discharges in the neostriatum and DRN, 1.0 or 7.5 $\mathrm{mg} / \mathrm{kg}$ of $d$-AMPH sulfate (free base) was injected in some animals via an indwelling intraperitoneal catheter. The accuracy of the intraperitoneal injection was verified at the end of the experiment when methylene blue dye was injected through the catheter and the peritoneal cavity was subsequently inspected. Data obtained from animals in which dye was found outside the peritoneal cavity were discarded. Each rat received only one injection of $d$-AMPH to avoid residual drug effects.

Histological analysis. Upon completion of the experiment, the animal received a lethal dose of sodium pentobarbital (Nembutal), and current was passed through the recording electrodes to make a small lesion. Following a transcardial perfusion with normal saline and $10 \%$ formalin, the brain was removed, frozen, sectioned, and stained with cresyl violet for histological analysis.

\section{Results}

Neostriatal activity following a $d$-AMPH-induced inhibition of the DRN. A local infusion of $d-\mathrm{AMPH}$ into the DRN of 25 animals suppressed the firing rate in this site and produced a mirror-image excitation in the neostriatum, but only in the ventral, lateral, or extreme anterior region. Figure 1 illustrates the time course of this inverse relationship as it occurred in one animal following an infusion of $1 \times 10^{-5} \mathrm{M} d$-AMPH into the DRN. These results have been replicated in 12 additional animals and, in each case, a $d$-AMPH-induced depression in the DRN was accompanied by an equally prolonged excitation in the same circumscribed region of the neostriatum. Table I depicts this relationship for all neurons in the DRN and those in the neostriatum that responded with an cxcitation.

A substantial number of neostriatal neurons $(n=12)$ failed to change their firing rate following an inhibition in the DRN. In fact, these cells did not deviate from their base line rate for as long as $60 \mathrm{~min}$ after the $d-\mathrm{AMPH}$ infusion. Histological analysis revealed that these nonresponding neurons were generally confined to the dorsal or medial half of the anterior neostriatum. Figure 2 illustrates the distribution of electrode tip placements within the neostriatum as a function of the neuronal response. Note that with the exception of the most anterior placements shown in section A 9410, a clear separation exists between the medial and lateral halves of the neostriatum. Moreover, in our most posterior recordings, the nonresponding cells occupied the medial region along the border of the globus pallidus; more distant placements routinely recorded an increase in firing rate. In all subsequent experiments, recordings from the ventrolateral neostriatum were obtained from a region at least $2.0 \mathrm{~mm}$ ventral to the neostriatal surface or within $1.5 \mathrm{~mm}$ of the lateral edge of the neostriatum.

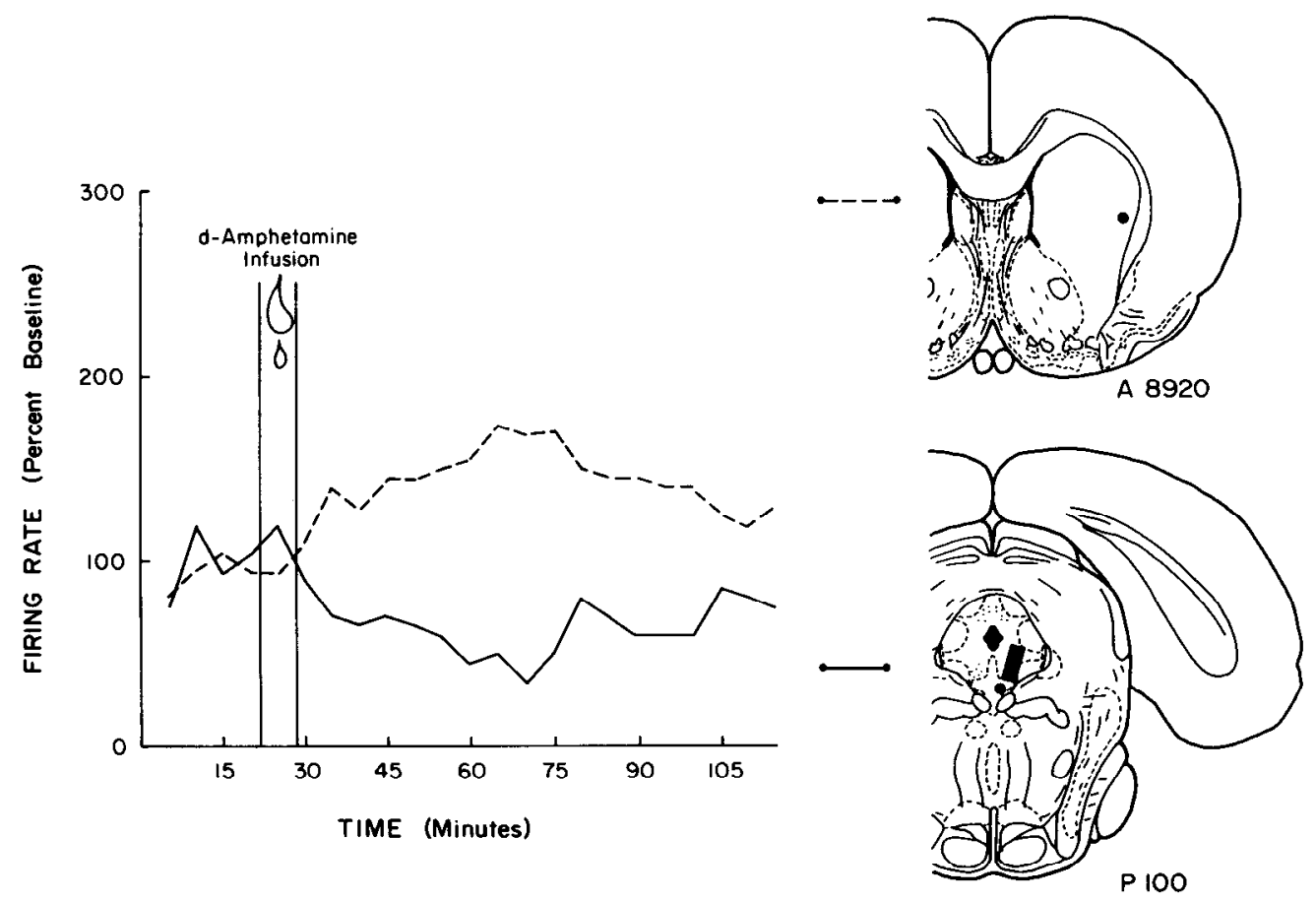

Figure 1. Representative examples of the mirror-image response in the DRN and neostriatum following an infusion of $1 \times$ $10^{-5} \mathrm{M} d$-AMPH into the DRN. The drug was infused for $6 \mathrm{~min}$, as indicated by the tall parallel lines, at a rate of $1.2 \mu \mathrm{l} / \mathrm{hr}$ resulting in a total infusion volume of $0.12 \mu \mathrm{l}$. Neuronal activity in both sites is plotted as a percentage change from the preinfusion hase line rate which was defined as $100 \%$. The positions of the recording electrodes and the infusion cannula with its approximate angle of entry are illustrated to the right of the graph. Histological drawings in this and subsequent figures are after König and Klippel (1963). 
Placements less than $1.5 \mathrm{~mm}$ from the ventricular border or within $0.5 \mathrm{~mm}$ of the globus pallidus were defined as dorsomedial recordings.

An infusion of $d$-AMPH into the periaqueductal gray or brainstem reticular formation, at distances of $800 \mu \mathrm{m}$ or more from the DRN, produced no change in DRN activity $(n=10)$ for as long as $50 \mathrm{~min}$ after the onset of the infusion. In the neostriatum of these same animals, five neurons failed to respond, three were excited, and two were depressed with no apparent regional differences characterizing these responses. In three additional animals, an infusion of normal saline into the DRN failed to change activity in either this site or the neostriatum.

A separate group of animals $(n=10)$ was pretreated with $250 \mathrm{mg} / \mathrm{kg}$ of $\alpha$-MT (i.p.) approximately $3 \mathrm{hr}$ before the recording session to deplete brain catecholamines (Cox and Maickel, 1975; Widerlov, 1979). Following the isolation of single unit discharges in the DRN and in the ventrolateral neostriatum, a local infusion of $d-\mathrm{AMPH}$ into the DRN continued to elicit the same inverse relationship obtained in non-pretreated rats (Table I). Note that $\alpha$-MT had no significant effect on either the peak

TABLE I

Neuronal responses to a local infusion of $d-A M P H$ into the $D R N$

\begin{tabular}{cccc}
\hline Pretreatment & Response & $\begin{array}{c}\text { Peak Response } \\
(\% \text { base line })\end{array}$ & Duration (min) \\
\hline None & $\begin{array}{c}\text { Excitation in neos- } \\
\text { triatum }(n=13) \\
\text { Inhibition in DRN }(n \\
=17)\end{array}$ & $399( \pm 57.2)$ & $61( \pm 5.5)$ \\
$\alpha$ MT $^{a}$ & $\begin{array}{c}\text { Excitation in neos- } \\
\text { triatum }(n=5) \\
\text { Inhibition in DRN }(n \\
=10)\end{array}$ & $295( \pm 75.4)$ & $66( \pm 14.5)$ \\
& $94.1)$ & $61( \pm 11.2)$ \\
\hline
\end{tabular}

${ }^{a}$ A separate group of animals received $250 \mathrm{mg} / \mathrm{kg}$ of $\alpha-\mathrm{MT} 3 \mathrm{hr}$ before the recording session. or the duration of the response in the ventrolateral neostriatum or DRN.

Reciprocal changes in firing rate produced by $5-\mathrm{Me}$ $O D M T$. If the acceleration of firing rate in the ventrolateral neostriatum following inhibition of the DRN is mediated by a decrease in neostriatal $5-\mathrm{H}$ T release, then a systemic injection of 5 -methoxy- $N, N$-dimethyltryptamine (5-MeODMT), which suppresses DRN impulse flow by acting on 5-HT autoreceptors (de Montigny and Aghajanian, 1977; Mosko and Jacobs, 1977), should produce comparable results. To test this hypothesis, a separate group of rats, previously fitted with a jugular catheter, received an intravenous injection of $20 \mu \mathrm{g} / \mathrm{kg}$ of 5 MeODMT. In each case $(n=5)$, the firing rate was suppressed in the DRN for 8 to 12 min and simultaneously elevated in the ventrolateral neostriatum. The results of one of these experiments are shown in Figure 3 . Note that, in this case, both units continued to fire in a reciprocal pattern even after the return to their respective base line rates. No 5-MeODMT-induced change in dorsomedial activity was recorded in five additional animals.

DRN lesions. Further evidence for a regional dichotomy between the ventrolateral and dorsomedial neostriatum was obtained following an acute electrolytic lesion of the DRN. Thus, seven neurons in the ventrolateral neostriatum of seven different animals responded to a lesion of the $\mathrm{DRN}$ with a dramatic increase in firing rate that began within $10 \mathrm{~min}$ and reached a mean maximum magnitude of $301( \pm 33.99) \%$ of the prelesion base line rate. In contrast, three neurons in the dorsomedial neostriatum failed to respond within the first $30 \mathrm{~min}$ after a DRN lesion and two dorsomedial neurons showed an increasse to only $150 \%$ of base line that lasted for less than $20 \mathrm{~min}$. Histological analysis revealed that in all cases the DRN lesion was extensive, encroaching on the border of the periaqueductal gray. Representative record-

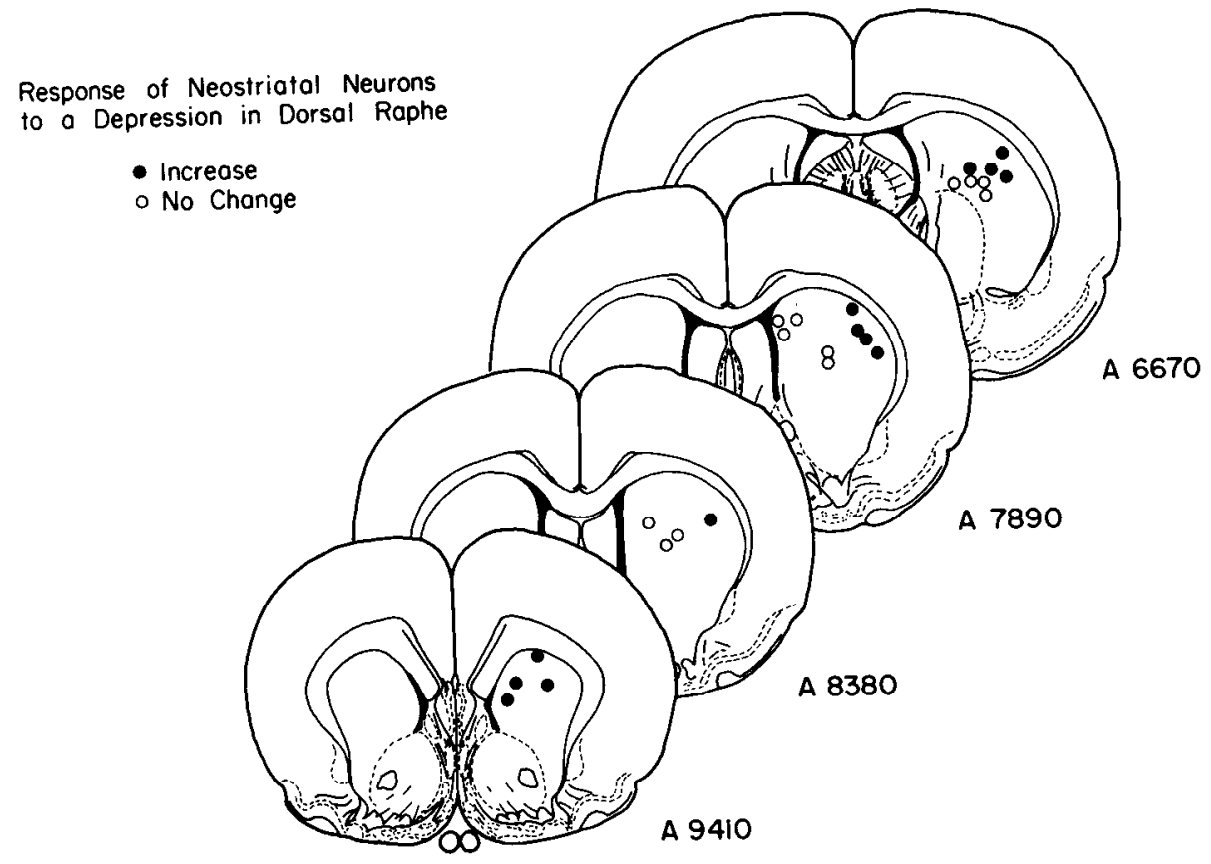

Figure 2. Locations in the neostriatum of electrode placements that recorded an increase (solid circles) or no change (open circles) in firing rate following a $d$-AMPH-induced depression in the DRN. 


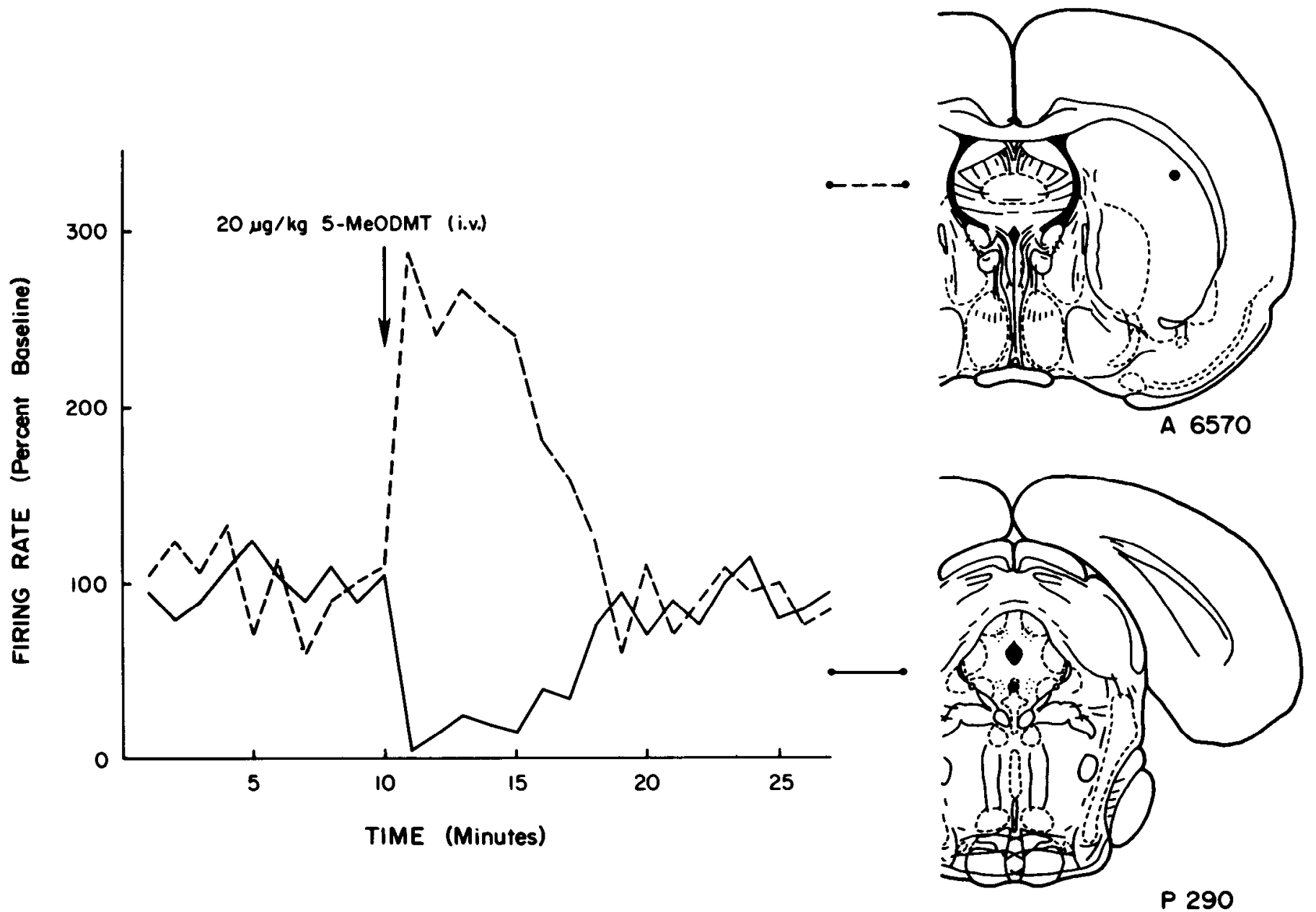

Figure 3. Reciprocal changes in firing rate in the DRN and ventrolateral neostriatum produced in one animal by $20 \mu \mathrm{g} / \mathrm{kg}$ of 5-MeODMT (i.v. at arrow). Neuronal activity is plotted as in Figure 1.

ings from the ventrolateral and dorsomedial neostriatum following a DRN lesion are shown in Figure 4.

Dose-dependent effects of $d-A M P H$. When injected systemically, $d$-AMPH also produced a regional dichotomy in the responsiveness of nenstriatal neurons. As shown in Figure 5, a dose-dependent shift in neostriatal activity from inhibition to excitation was confined to a population of cells along the medial half of the dorsal neostriatum within $1.5 \mathrm{~mm}$ of the lateral ventricle, whereas more ventral and lateral placements recorded the opposite response.

In the dorsomedial neostriatum, an intraperitoneal injection of $1.0 \mathrm{mg} / \mathrm{kg}$ suppressed the activity of eight neurons recorded from eight different animals. In no case did we observe an increase in firing rate to this dose. An injection of $7.5 \mathrm{mg} / \mathrm{kg}$, on the other hand, routinely accelerated dorsomedial activity $(n=5)$. The excitation

an within $10 \mathrm{~min}$ after injection and, in all cases, eeded $200 \%$ of the base line rate. This dose-dependent ft in activity was reversed in the ventrolateral neostriatum. An intraperitoneal injection of $1.0 \mathrm{mg} / \mathrm{kg}$ of $d$-AMPH, for example, increased the firing rate of all 16 neurons that histological analysis revealed to be in this region. Following an injection of $7.5 \mathrm{mg} / \mathrm{kg}$, however, unit activity in the ventrolateral neostriatum $(n=7)$ was depressed. Moreover, there was no sign of an increase in activity prior to the depression which began in all cases within $15 \mathrm{~min}$ after the injection.
This regional dichotomy was confirmed by statistical analysis. The mean percentage of firing rate during the first $30 \mathrm{~min}$ after an injection of $1.0 \mathrm{mg} / \mathrm{kg}$ of $d$-AMPH in the dorsomedial neostriatum $(60.9 \pm 3.43 \%)$ was significantly different $(t=3.44 ; p<0.01)$ from that in the ventrolateral neostriatum $(279.9 \pm 15.51 \%)$. A similar difference, although in the opposite direction, was recorded following an injection of $7.5 \mathrm{mg} / \mathrm{kg}$ of $d-A M P H$. Thus, neurons in the dorsomedial region responded to this dose with a mean firing rate of $400.6( \pm 94.74) \%$ of the base line rate during the first $30 \mathrm{~min}$ after the injection, whereas ventrolateral neurons responded during the same period with a mean firing rate of $59.0( \pm$ $4.87) \%$ of the base line rate $(t=2.42 ; p<0.05)$.

Neurons in the DRN also responded to $d$-AMPH with a dose-dependent shift in activity, but in this case the response was inversely related to that in the ventrolateral neostriatum. Thus, whereas $1.0 \mathrm{mg} / \mathrm{kg}$ suppressed impulse flow in the DRN, $7.5 \mathrm{mg} / \mathrm{kg}$ produced a prolonged excitation. Moreover, as shown in Table II, the time course of the DRN response paralleled the time course of the response in the ventrolateral, but not dorsomedial, neostriatum. Figure 6 illustrates this inverse relationship between the DRN and ventrolateral neostriatum as it occurred in one animal following an injection of $1.0 \mathrm{mg} /$ $\mathrm{kg}$. Note also that the overall duration of the response in both sites is comparable. Even at the high dose, neurons in both the DRN and the ventrolateral neostria- 
tum return to base line at approximately the same time. A dramatic example of this effect is shown in Figure 7.

Recordings in the brainstem reticular formation of 10 different animals revealed a monotonic increase in firing rate regardless of dose. Thus, consistent with previous reports (Boakes et al., 1972; Rebec and Groves, 1975), $1.0 \mathrm{mg} / \mathrm{kg}$ of $d$-AMPH accelerated activity in all seven reticular formation neurons for approximately $60 \mathrm{~min}$ and a similar, although more prolonged, response was observed in three reticular formation neurons following administration of the high dose. No $d$-AMPH-induced depressions were observed in the brainstem reticular formation.

\section{Discussion}

Our results clearly indicate that a change in DRN activity does not produce uniform effects throughout the neostriatum. In the ventrolateral region, neurons respond to a suppression of DRN activity with an equally prolonged excitation. Dorsomedial neurons, on the other hand, fail to respond. In fact, these neurons remain unresponsive after an electrolytic lesion of the DRN, arguing against a widespread influence of this nucleus on neostriatal neurons. This regional differentiation within the neostriatum parallels neuroanatomical evidence on the distribution of DRN terminals. They have been identified, for example, along the ventral and lateral edges of the neostriatum with a small projection to the extreme anterior extent of this structure (Conrad et al., 1974; Ternaux et al., 1977; Azmitia and Segal, 1978; Steinbusch, 1981) - the same areas that in our study respond to changes in DRN activity. DRN terminals are virtually absent in the dorsomedial neostriatum and, accordingly, we found that neurons in this region are uninfluenced by a change in DRN impulse flow. It appears, therefore, that the neostriatum can be divided into two separate and functionally independent regions based on the degree of control exerted by the DRN.

The increase in ventrolateral activity that occurs following a reduction of impulse flow in the DRN can be
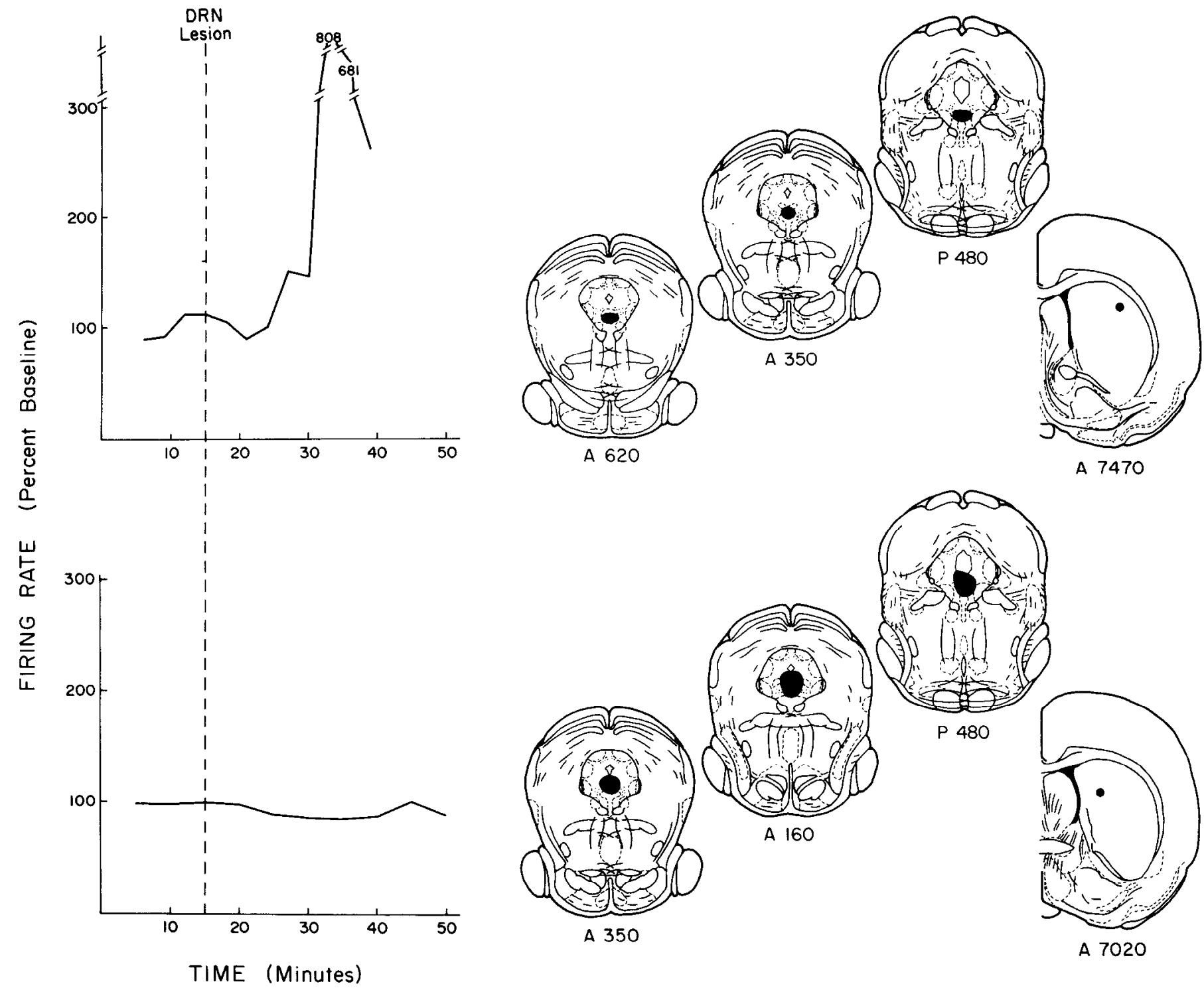

Figure 4. Effects of an electrolytic lesion of the DRN on neuronal activity in the ventrolateral (top) and dorsomedial (bottom) neostriatum. The lesion site and the placement of the recording electrode are illustrated to the right of the graph. Neuronal activity is plotted as in Figure 1. 

- DEPRESSION TO 1.0 OR EXCITATION TO $7.5 \mathrm{mg} / \mathrm{kg}$
d-AMPHETAMINE

A EXcitation TO 1.0 OR DEPRESSION TO $7.5 \mathrm{mg} / \mathrm{kg}$ d-AMPHETAMINE

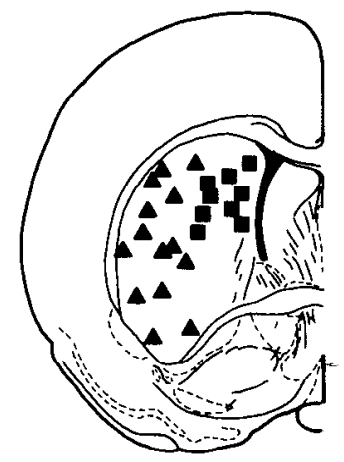

A 7190

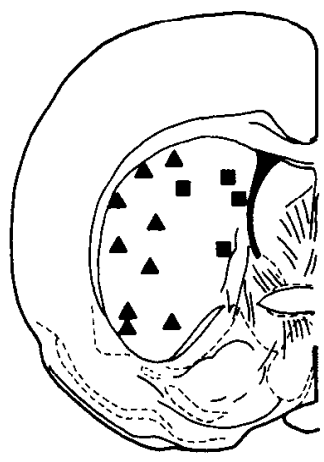

A 7020

Figure 5. Regional differences within the neostriatum of the dose-dependent response to $d$-AMPH. Note that neurons excited by a low dose and inhibited by a high dose are confined to the ventrolateral neostriatum, whereas neurons responding in the opposite fashion are located in the dorsomedial neostriatum.

explained by a release of postsynaptic neurons from 5 $\mathrm{HT}$ inhibition. That 5-HT normally inhibits neostriatal activity is supported by evidence that electrical stimulation of the DRN suppresses neostriatal firing rate (Miller et al., 1975; Olpe and Koella, 1977; Godukhin, 1979; Yamamoto and Murayama, 1980) and that this effect is reversed by 5-HT antagonists (Olpe and Koella, 1977). Iontophoretic application of 5-HT has also been reported to inhibit neostriatal neurons (Herz and Zieglgansberger, 1968; Olpe and Koella, 1977). In fact, several lines of evidence make it unlikely that our results in the ventrolateral neostriatum are independent of a change in $5-\mathrm{HT}$ impulse flow. For one, we have previously shown that the inhibition of DRN activity produced by a local infusion of $d$-AMPH into this site reflects the local release of 5-HT onto inhibitory autoreceptors (Rebec et al., 1982 ). This view is consistent with reports that $d$-AMPH increases the extracellular concentration of 5-HT in the DRN (Geyer et al., 1975) and that iontophoretic application of 5-HT inhibits the firing rate of DRN neurons (Aghajanian and Haigler, 1975; Bramwell and Gönye, 1976; Rogawski and Aghajanian, 1981). In addition, a systemic injection of 5-MeODMT, at a dose that selectively acts on 5-H'T autoreceptors (de Montigny and Aghajanian, 1977; Mosko and Jacobs, 1977), mimicked

the effect of a local $d$-AMPH infusion: a suppression of impulse flow in the DRN and a mirror-image excitation in the ventrolateral neostriatum. Moreover, quipazine, a postsynaptic 5-HT agonist, has been reported to inhibit cholinergic neurons in the ventral, but not dorsal, neostriatum (Guyenet et al., 1977). It is also unlikely that $d$-AMPH is acting at some remote site since an infusion of this drug more than $800 \mu \mathrm{m}$ away from the DRN had no effect on DRN activity and no consistent effect on neostriatal neurons.

Recently, Park et al. (1982) suggested that the apparently inhibitory influence of the DRN on neostriatal firing rate is mediated by a multisynaptic pathway. Although we cannot rule out this possibility, our results suggest that such a pathway does not include catecholaminergic neurons. Thus, a depletion of catecholamines by $\alpha-\mathrm{MT}$, administered at a dose and pretreatment time that have been shown to block catecholaminergic transmission (Boakes et al., 1972; Groves et al., 1976; Stone, 1976), failed to alter the inverse relationship between DRN and ventrolateral neostriatal activity. Furthermore, dopamine (DA)-containing neurons in the substantia nigra, which receive input from the DRN, project mainly to the dorsomedial neostriatum (Fallon and Moore, 1978; Di Paolo et al., 1982), and yet the firing rate of dorsomedial neurons has no apparent relationship to neuronal activity in the DRN. It is unlikely, therefore, that our results can be explained by a DRN modulation of catecholaminergic neurons.

A dichotomy between the dorsomedial and ventrolateral neostriatum also cmerged following systemic injections of $d$-AMPH and, again, the DRN appeared to control ventrolateral, but not dorsomedial, activity. Thus, whereas the time course of the response in the dorsomedial neostriatum was significantly different from that in the DRN at both doses of $d$-AMPH, the ventrolateral response peaked and returned to base line at the same time as that in the DRN. Moreover, the inverse relationship between ventrolateral and DRN activity lends further support to the notion of a tonic inhibition by $5-\mathrm{HT}$ on neurons in this region of the neostriatum. In fact, relatively high doses of $d$-AMPH $(5.0 \mathrm{mg} / \mathrm{kg}$ or more) are required to increase 5 -HT release in the neostriatum (Fuxe and Ungerstedt, 1970; Rutledge et al., 1972; Tseng et al., 1976) and it is the high dose that suppresses

TABLE II

Time course of $d-A M P H$-induced changes in neuronal activity in the neostriatum and $D R N$

\begin{tabular}{cccc}
\hline -AMPH & Brain Region & $\begin{array}{c}\text { Latency to } \\
\text { Peak Effect }\end{array}$ & Duration \\
$m g / k g$ & & \multicolumn{2}{c}{$\min$} \\
1.0 & Neostriatum & & \\
& dorsomedial $(n=8)$ & $46( \pm 9.5)^{a}$ & $68( \pm 11.5)^{a}$ \\
& ventrolateral $(n=16)$ & $29( \pm 5.8)$ & $57( \pm 9.1)$ \\
& DRN $(n=9)$ & $26( \pm 5.6)$ & $46( \pm 6.4)$ \\
7.5 & Neostriatum & & \\
& dorsomedial $(n=5)$ & $48( \pm 7.2)^{a}$ & $68( \pm 18.7)^{a}$ \\
& ventrolateral $(n=7)$ & $103( \pm 28.6)$ & $202( \pm 43.0)$ \\
& DRN $(n=6)$ & $94( \pm 22.5)$ & $137( \pm 20.4)$ \\
\hline
\end{tabular}

${ }^{a} p<0.05$ compared to corresponding DRN response. 


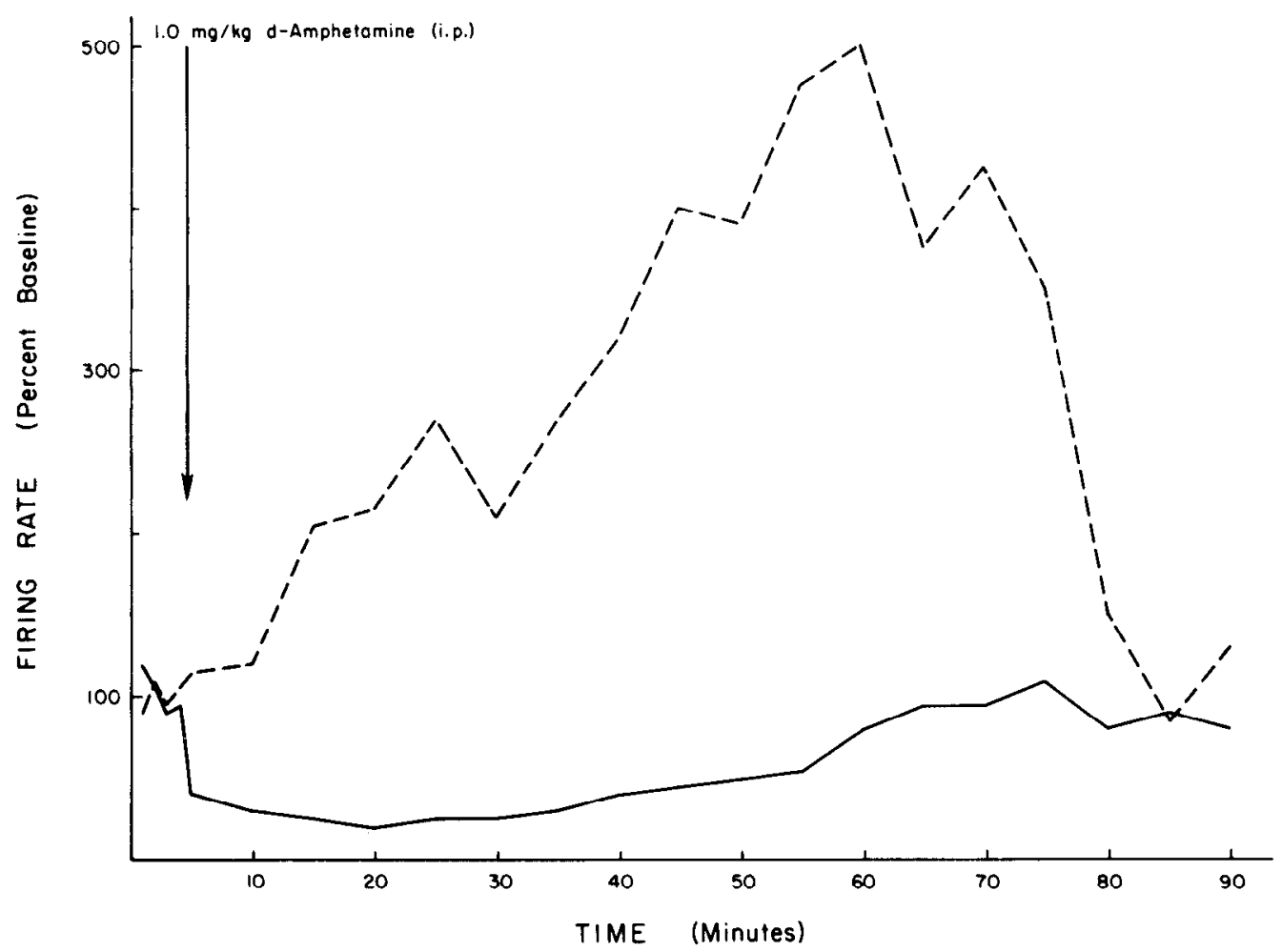

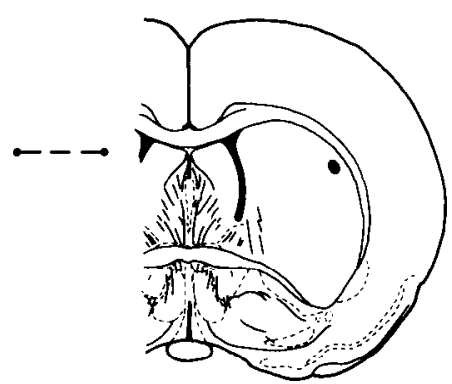

A 7190

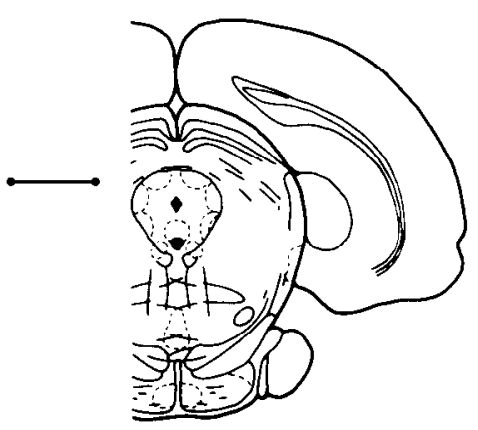

A 620

Figure 6. Representative example of the opposite effects of $1.0 \mathrm{mg} / \mathrm{kg}$ of $d$-AMPH (i.p.; at arrow) on neuronal activity in the DRN and ventrolateral neostriatum. Firing rate is plotted as a percentage change from the $100 \%$ base line rate in Figure 1.
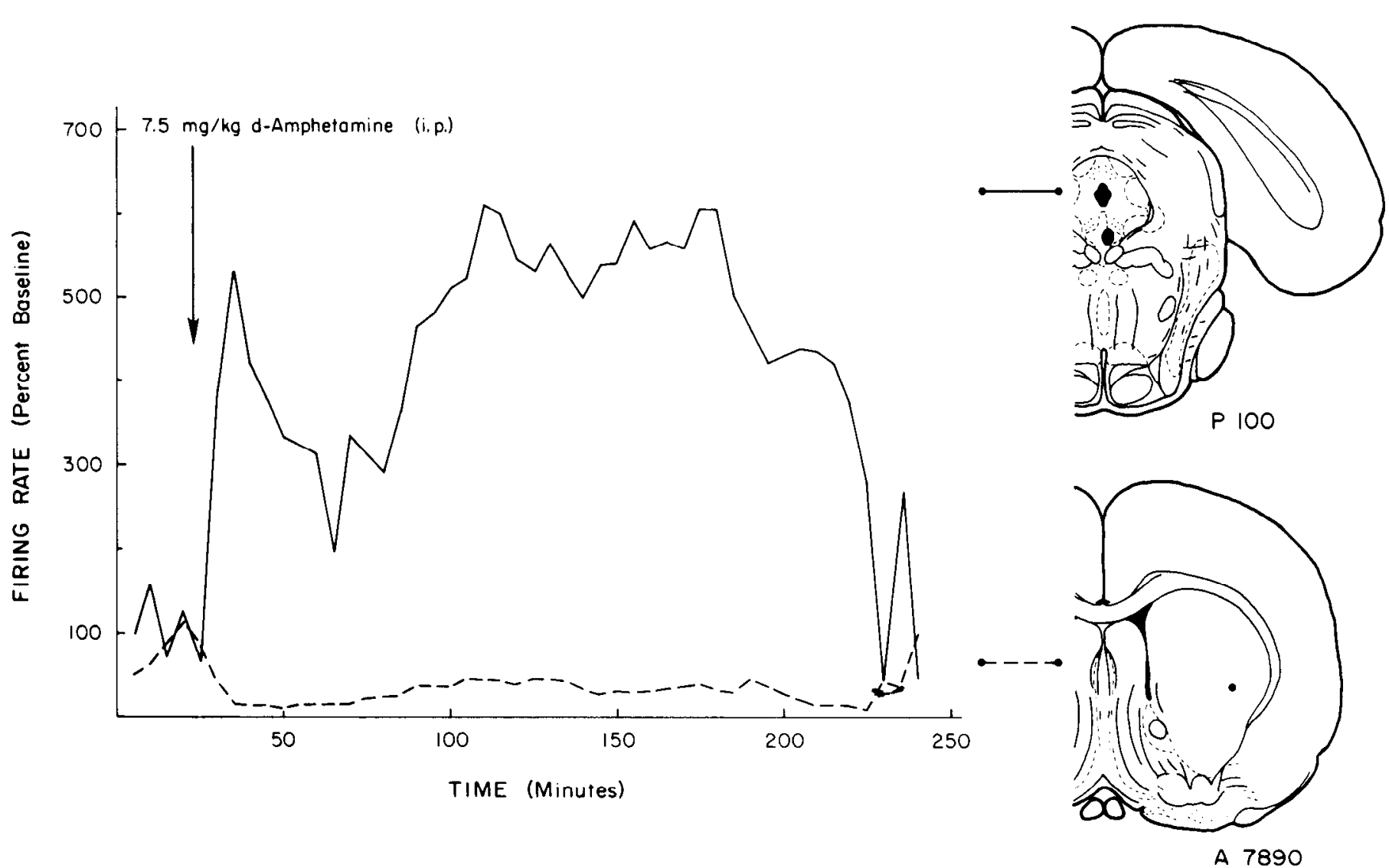

Figure 7. Response to $7.5 \mathrm{mg} / \mathrm{kg}$ of $d$-AMPH (i.p.; at arrow) of neurons recorded simultaneously in the DRN and ventrolateral ncostriatum. Note again the reciprocal change in firing rate and note that this response is the opposite of that produced by a low dose of the drug. Neuronal activity is plotted as in Figure 1. 
ventrolateral activity. In the dorsomedial neostriatum, 5 -HT appears to influence the $d$-AMPH response only indirectly. A depletion of $5-\mathrm{HT}$, for example, alters but does not abolish the response of dorsomedial neurons to either 1.0 or $7.5 \mathrm{mg} / \mathrm{kg}$ (Rebec et al., 1981). DA antagonists, on the other hand, block both the $d$-AMPH-induced inhibition and excitation, suggesting a strong dopaminergic influence in this region of the neostriatum (Bashore et al., 1978; Rebec and Segal, 1978; Rebec et al., 1979; Rebec and Zimmerman, 1980). It appears, therefore, that regional differences in dopaminergic and serotonergic innervation of the neostriatum provide a neuroanatomical basis for functional heterogeneity within this structure.

This view is consistent with an accumulating body of evidence that the neostriatum is composed of several distinct neurochemical compartments. Substance P fibers, for example, arise from the anterior neostriatum, whereas neostriatal efferents containing $\gamma$-aminobutyric acid are localized in the caudal neostriatum (Gale et al., 1977; Hong et al., 1977; Kanazawa et al., 1977). Moreover, high affinity choline uptake, a marker for cholinergic nerve terminals, is highest in the dorsal and lateral neostriatum but lowest in the center (Takano et al., 1980; Rea and Simon, 1981). In fact, Graybiel and Ragsdale (1978) have divided the neostriatum into histological compartments or "striosomes" based on the degree of acetylcholinesterase activity in each. Recently, uneven distributions of enkephalin and other neuropeptides have also been identified in the neostriatum (Pickel et al., 1980; Graybiel et al., 1981).

The dose-dependent shift in DRN activity was somewhat surprising in view of previous reports that $d$-AMPH accelerates DRN activity, at least in part, by facilitating the release of norepinephrine from DRN afferents (Gallager and Aghajanian, 1976; Baraban et al., 1978). Although this action may explain our results following a high systemic dose of $d$-AMPH, low doses suppress firing rate in the DRN. In fact, 5 -MeODMT also suppresses DRN activity, and this response is blocked by methiothepin, a putative blocker of 5-HT autoreceptors (Rebec et al., 1982). Thus, as in our infusion experiments, $d$-AMPH may inhibit DRN activity by facilitating the local release of 5-HT. High systemic doses may simply mask this effect by releasing sufficient norepinephrine to accelerate DRN impulse flow.

When combined with our results in the neostriatum, this dose-dependent shift in DRN activity permits some speculation about the mechanism by which 5 -HT may modulate the dose-dependent behavioral response to $d$ AMPH. It is well known, for example, that a depletion of 5-HT potentiates the locomotor response to a low dose of $d$-AMPH but reduces the focused stereotyped behavior produced by high doses of the drug (Segal, 1976; Sloviter et al., 1978; Lucki and Harvey, 1979). Thus, whereas $d$ AMPH-induced locomotion may not require 5-HT and may actually correspond to a decrease in 5-HT release, focused stereotypy appears to reflect, in part, an increase in 5-HT release. Interestingly, damage to the ventral but not the dorsal neostriatum has been reported to abolish $d$-AMPH-induced stereotypy (Neill et al., 1974). Thus, to the extent that the ventrolateral neostriatum is con- trolled by 5 -HT, it is tempting to speculate that $5-\mathrm{HT}$ control of the behavioral transition from locomotion to focused stereotypy is mediated, in large measure, by the ventrolateral neostriatum. Neostriatal 5-HT has also been implicated in the psychotic behavior associated with $d$-AMPH abuse in humans (Trulson and Jacobs, 1979) and in the tardive dyskinesia produced by the antipsychotic drugs (Nagao et al., 1979; Berger and Rexroth, 1980). In fact, a growing body of evidence implicates a 5H'T dysfunction in Parkinson's disease, manic-depressive psychosis, and many other neurological and psychiatric disorders (e.g., Chase and Murphy, 1973; Dray, 1981). Careful monitoring of 5-HT transmission within specific regions of the neostriatum, therefore, may shed new light on the neuronal systems underlying a variety of human diseases.

\section{References}

Aghajanian, G. K., and H. J. Haigler (1975) Hallucinogenic indoleamines: Preferential action upon presynaptic serotonin receptors. Psychopharmacol. Commun. 1: 619-629.

Alloway, K. D., and G. V. Rebec (1983) Shift from inhibition to excitation in the neostriatum but not in the nucleus accumbens following long-term amphetamine. Brain Res., in press.

Azmitia, E. C., and M. Segal (1978) An autoradiographic analysis of the differential ascending projections of the dorsal and median raphe nuclei in the rat. J. Comp. Neurol. 179: 641-668.

Baraban, J. M., R. Y. Wang, and G. K. Aghajanian (1978) Reserpine suppression of dorsal raphe neuronal firing: $\mathrm{Me}$ diation by adrenergic systems. Eur. J. Pharmacol. 52: 27-36.

Bashore, T. R., G. V. Rebec, and P. M. Groves (1978) Alterations of spontaneous neuronal activity in the caudate-putamen, nucleus accumbens and amygdaloid complex of rats produced by $d$-amphetamine. Pharmacol. Biochem. Behav. 8: 467-474.

Berger, P. A., and K. Rexroth (1980) Tardive dyskinesia: Clinical, biological, and pharmacological perspectives. Schizophr. Bull. 6: 102-116.

Bloom, F. E., E. Costa, and G. C. Salmoiraghi (1965) Anesthesia and the responsiveness of individual neurons of the caudate nucleus of the cat to acetylcholine, norepinephrine and dopamine administered by microelectrophoresis. J. Pharmacol. Exp. Ther. 150: 244-252.

Boakes, R. J., P. B. Bradley, and J. M. Candy (1972) A neuronal basis for the alerting action of $(+)$-amphetamine. Br. J. Pharmacol. 45: 391-403.

Bramwell, G. J., and T. Gönye (1976) Responses of midbrain neurons to microiontophoretically applied 5-hydroxy-tryptamine: Comparison with the response to intravenously administered lysergic acid diethylamide. Neuropharmacology 15: $457-461$.

Carter, C. J. (1982) Topographical distribution of possible glutamatergic pathways from the frontal cortex to the striatum and substantia nigra in rats. Neuropharmacology 21: 379-383.

Chang, H. T., C. J. Wilson, and S. T. Kitai (1982) A Golgi study of rat neostriatal neurons: Light microscopic analysis. J. Comp. Neurol. 208: 107-126.

Chase, T. N., and D. L. Murphy (1973) Serotonin and central nervous system functions. Annu. Rev. Pharmacol. 13: 181197.

Connor, J. D. (1975) Electrophysiology of the nigro-caudate dopamine pathway. Pharmacol. Ther. 3: 357-370.

Conrad, L. C. A., C. M. Leonard, and D. W. Pfaff (1974) 
Connections of the medial and dorsal raphe nuclei in the rat: An autoradiographic and degeneration study. J. Comp. Neurol. 156: 179-205.

Cox, R. H., and R. P. Maickel (1975) Differential effects of $\alpha \mathrm{MT}$ on anorectic and stimulatory action of amphetamines. Res. Commun. Chem. Pathol. Pharmacol. 12: 621-626.

de Montigny, C., and G. K. Aghajanian (1977) Preferential action of 5-methoxytryptamine and 5-methoxydimethyltryptamine on presynaptic serotonin receptors: A comparative iontophoretic study with LSD and serotonin. Neuropharmacology 16: 811-818.

Di Paolo, T., M. Daigle, and A. Dupont (1982) Distribution of dopamine in 35 subregions of the rat caudate-putamen: A high performance liquid chromatography with electrochemical detection analysis. J. Can. Sci. Neurol. (November): 421427.

Divac, I, and N. H. Diemer (1980) Prefrontal system in the rat visualized by means of labeled deoxyglucose-Further evidence for functional heterogeneity of the neostriatum. J. Comp. Neurol. 190: 1-13.

Divac, I., and R. G. E. Öberg (1979) Current conceptions of neostriatal functions: History and an evaluation. In The Neostriatum, I. Divac and R. G. E. Öberg, eds., pp. 215-230, Pergamon Press, New York.

Dray, A. (1980) The physiology and pharmacology of mammalian basal ganglia. Prog. Neurobiol. 14: 221-335.

Dray, A. (1981) Serotonin in basal ganglia: Functions and interactions with other neuronal pathways. J. Physiol. (Paris) 77: 393-403.

Dunnett, S. B., and S. D. Iverson (1982) Neurotoxic lesions of ventrolateral but not anteromedial neostriatum in rats impair differential reinforcement of low rated (DRL) performance. Behav. Brain Res. 136: 487-500.

Fallon, J. H., and R. Y. Moore (1978) Catecholamine innervation of the basal forebrain. Topography of the dopamine projection to the basal forebrain and neostriatum. J. Comp. Neurol. 180: 545-580.

Feltz, P., and D. Albe-Fessard (1972) A study of an ascending nigro-caudate pathway. Electroencephalogr. Clin. Neurophysiol. 33: 179-193.

Fuxe, K., and U. Ungerstedt (1970) Histochemical, biochemical and functional studies on central monoamine neurons after acute and chronic amphetamine administration. In Amphetamines and Related Compounds, F. Costa and S. Garattini, eds., pp. 257-300, Raven Press, New York.

Gale, K., J. -S. Hong, and A. Guidotti (1977) Presence of substance $P$ and GABA in separate striatonigral neurons. Brain Res. 136: 371-375.

Gallager, D. W., and G. K. Aghajanian (1976) Effect of antipsychotic drugs on the firing of dorsal raphe cells. Role of adrenergic system. Eur. J. Pharmacol. 39: 341-355.

Geyer, M. A., W. J. Dawsey, and A. J. Mandell (1975) Differential effects of caffeine, D-amphetamine and methylphenidate on individual raphe cell fluorescence: A microspectrofluorimetric demonstration. Brain Res. 85: 135-139.

Godukhin, O. (1979) Electrophysiological analysis of rat neostriatum afferent inputs interaction. Neurophysiologia 11: $382-385$.

Graybiel, A. M., and C. W. Ragsdale (1978) Histochemically distinct compartments in the striatum of human, monkey and rat demonstated by acetylcholinesterase staining. Proc. Natl. Acad. Sci. U. S. A. 75: 5723-5726.

Graybiel, A. M., C. W. Ragsdale, Jr., E. S. Yoneoka, and R. P. Elde (1981) An immunohistochemical study of enkephalins and other neuropeptides in the striatum of the cat with evidence that the opiate peptides are arranged to form mosaic patterns in register with the striosomal compartments visible by acetylcholinesterase staining. Neuroscience 8: 377-395.
Groves, P. M., C. J. Wilson, S. J. Young, and G. V. Rebec (1975) Self-inhibition by dopaminergic neurons. Science 190: $522-529$.

Groves, P. M., S. J. Young, and C. J. Wilson (1976) Selfinhibition by dopaminergic neurons: Disruption by $( \pm)-\alpha-$ methyl- $p$-tyrosine pretreatment or anterior diencephalic lesions. Neuropharmacology 15: 755-762.

Guyenet, P., C. Euvrad, F. Javoy, A. Herbert, and J. Glowinski (1977) Regional differences in the sensitivity of cholinergic neurons to dopaminergic drugs and quipazine in the rat striatum. Brain Res. 136: 487-500.

Herz, A., and W. Zieglgansberger (1968) The influence of microelectrophoretically applied biogenic amines, cholinomimetics and procaine on synaptic excitation in the corpus striatum. Int. J. Neuropharmacol. 7: 221-230.

Hong, J. -S., H. - Y. T. Yang, G. Racagni, and E. Costa (1977) Projections of substance $P$ containing neurons from neostriatum to substantia nigra. Brain Res. 122: 541-544.

Kanazawa, I., P. C. Emson, and A. C. Cuello (1977) Evidence for the existence of substance P-containing fibres in striatonigral and pallido-nigral pathways in rat brain. Brain Res. 119: 447-453.

Kelley, A. E., V. B. Domesick, and W. J. H. Nauta (1982) The amygdalostriatal projection in the rat An anatomical study by anterograde and retrograde tracing methods. Neuroscience 7: $615-630$.

Kitai, S. T., R. J. Preston, G. A. Bishop, and J. D. Kocsis (1979) Striatal projection neurons: Morphological and electrophysiological studies. Adv. Neurol. 21: 15-51.

König, J. F. R., and R. A. Klippel (1963) The Rat Brain: A Stereotaxic Atlas of the Forebrain and Lower Parts of the Brain Stem, The Williams and Wilkins Co., Baltimore.

Lucki, I., and J. A. Harvey (1979) Increased sensitivity to Dand $\mathrm{L}$-amphetamine action after midbrain raphe lesions as measured by locomotor activity. Neuropharmacology 18 : 243-249.

Mensah, P. L. (1977) The internal organization of the mouse caudate nucleus: Evidence for cell clustering and regional variation. Brain Res. 137: 53-66.

Miller, J. J., T. L. Richardson, H. C. Fibiger, and H. McLennan (1975) Anatomical and electrophysiological identification of a projection from the mesencephalic raphe to the caudateputamen in the rat. Brain Res. 97: 133-138.

Mosko, S. S., and B. I. Jacobs (1977) Flectrophysiological evidence against negative neuronal feedback from the forebrain controlling midbrain raphe unit activity. Brain Res. 119: 291-303.

Nagao, T., T. Ohshimo, K. Mitsunobu, M. Sato, and S. Otsuki (1979) Cerebrospinal fluid monoamine metabolites and cyclic nucleotides in chronic schizophrenic patients with tardive dyskinesia or drug-induced tremor. Biol. Psychiatry 14: 509523.

Neill, D. B., W. O. Boggan, and S. P. Grossman (1974) Behavioral effects of amphetamine in rats with lesions in the corpus striatum. J. Comp. Physiol. Psychol. 86: 1019-1030.

Neill, D. B., L. A. Peay, and M. S. Gold (1978) Identification of a subregion within rat neostriatum for the dopaminergic modulation of lateral hypothalamic self-stimulation. Brain Res. 153: 515-528.

Olpe, H. R., and W. P. Koella (1977) The response of striatal cells upon stimulation of the dorsal and median raphe nuclei. Brain Res. 122: 357-360.

Park, M. R., J. A. Gonzales-Vegas, and S. T. Kitai (1982) Serotonergic excitation from dorsal raphe stimulation recorded intracellularly from rat caudate-putamen. Brain Res. 243: 49-58

Pickel, V. M., K. K. Sumal, S. C. Beckley, R. J. Miller, and D. J. Reis (1980) Immunocytochemical localization of enke- 
phalin in the neostriatum of rat brain: A light and electron microscopic study. J. Comp. Neurol. 189: 721-740.

Rea, M. A., and J. R. Simon (1981) Regional distribution of cholinergic parameters within the rat striatum. Brain Res. 219: $317-326$.

Rebec, G. V., and P. M. Groves (1975) Differential effects of the optical isomers of amphetamine on neuronal activity in the reticular formation and caudate nucleus of the rat. Brain Res. 83: 301-318.

Rebec, G. V., and D. S. Segal (1978) Dose-dependent biphasic alterations in the spontaneous activity of neurons in the rat neostriatum produced by $\mathrm{D}$-amphetamine and methylphenidate. Brain Res. 150: 353-366.

Rebec, G. V., and K. S. Zimmerman (1980) Opposite effects of D-amphetamine on spontaneous neuronal activity in the neostriatum and nucleus accumbens. Brain Res. 201: 485491.

Rebec, G. V., T. R. Bashore, K. S. Zimmerman, and K. D. Alloway (1979) "Classical" and "atypical" antipsychotic drugs: Differential antagonism of amphetamine- and apomorphine-induced alterations of spontaneous neuronal activity in the neostriatum and nucleus accumbens. Pharmacol. Biochem. Behav. 11: 529-538.

Rebec, G. V., K. D. Alloway, and S. D. Curtis (1981) Apparent serotonergic modulation of the dose-dependent biphasic response of neostriatal neurons produced by $\mathrm{D}$-amphetamine. Brain Res. 210: 277-289.

Rebec, G. V., S. D. Curtis, and K. S. Zimmerman (1982) Dorsal raphe neurons: Self-inhibition by an amphetamine-induced release of endogenous serotonin. Brain Res. 251: 374-379.

Rocha-Miranda, C. E. (1965) Single unit analysis of cortexcaudate connections. Electroencephalogr. Clin. Neurophysiol. 19: 237-247.

Rogawski, M. A., and G. K. Aghajanian (1981) Serotonin autoreceptors on dorsal raphe neurons: Structure-activity relationships of tryptamine analogs. J. Neurosci. 1: 1148-1154.

Rutledge, C. O., A. J. Azzaro, and R. J. Ziance (1972) The role of monoamine oxidase in determining the amount of monoamines released by drugs in the central nervous system. Adv. Biochem. Psychopharmacol. 5: 379-392.

Segal, D. S. (1976) Differential effects of para-chlorophenylalanine on amphetamine-induced locomotion and stereotypy. Brain Res. 116: 267-276.

Sloviter, R. S., E. G. Drust, and J. D. Connor (1978) Evidence that serotonin mediates some behavioral effects of amphetamine. J. Pharmacol. Exp. Ther. 206: 348-352.

Steinbusch, H. W. M. (1981) Distribution of serotonin immunoreactivity in the central nervous system of the rat-Cell bodies and terminals. Neuroscience 4: 557-618.

Stone, T. W. (1976) Responses of neurones in the cerebral cortex and caudate nucleus to amantadine, amphetamine and dopamine. Br. J. Pharmacol. 56: 101-110.
Takano, Y., Y. Kohjimoto, K. Uchimura, and H. Kamiya (1980) Mapping of the distribution of high affinity choline uptake and choline acetyltransferase activity in the striatum. Brain Res. 194: 583-587.

Ternaux, J. P., F. Hery, S. Bourgin, J. Adrien, J. Glowinski, and M. Hamon (1977) The topographical distribution of serotonergic terminals in the neostriatum of the rat and the caudate nucleus of the cat. Brain Res. 121: 311-326.

Trulson, M. E., and B. L. Jacobs (1979) Chronic amphetamine administration to cats: Behavioral and neurochemical evidence for decreased central serotonergic function. J. Pharmacol. Exp. Ther. 211: 375-384.

Trulson, M. E., and V. M. Trulson (1983) Chloral hydrate anesthesia alters the responsiveness of dorsal raphe neurons to psychoactive drugs. Life Sci. 32: 949-956.

Tseng, L. F., M. K. Menon, and H. H. Loh (1976) Comparative actions of monomethoxyamphetamines on the release and uptake of biogenic amines in brain tissue. J. Pharmacol. Exp. Ther. 197: 263-271.

Van Der Kooy, D. (1979) The organization of the thalamic, nigral and raphe cells projecting to the medial vs. lateral caudate-putamen in the rat. A fluorescent retrograde double labeling study. Brain Res. 169: 381-387.

Veening, J. G., F. M. Cornelissen, and P. A. J. M. Lieven (1980) The topical organization of the afferents to the caudatoputamen of the rat. A horseradish peroxidase study. Neuroscience 5: 1253-1268.

Walaas, I. (1981) Biochemical evidence for overlapping neocortical and allocortical glutamate projections to the nucleus accumbens and rostral caudatoputamen in the rat brain. Neuroscience 6: 399-405.

Wang, R. Y., and G. K. Aghajanian (1977) Antidromically identified serotonergic neurons in the rat midbrain raphe: Evidence for collateral inhibition. Brain Res. 132: 186-193.

Wang, R. Y., and G. K. Aghajanian (1982) Correlative firing patterns of serotonergic neurons in rat dorsal raphe nucleus. J. Neurosci. 2: 11-16.

Widerlov, E. (1979) Dose-dependent pharmacokinetics of $\alpha$ methyl-p-tyrosine ( $\alpha$-MT) and comparison of catecholamine turnover rates after two doses of $\alpha$-MT. J. Neural Transm. 44: $145-158$.

Wilson, C. J., and P. M. Groves (1980) Fine structure and synaptic connections of the common spiny neuron of the rat neostriatum: A study employing intracellular injection of horseradish peroxidase. J. Comp. Neurol. 194: 599-615.

Yamamoto, M., and S. Murayama (1980) Effect of the serotonergic system on the caudate nucleus. Pharmacology 20:310315.

7arzecki, P., D. .J. Rlake, and G. G. Somjen (1976) Interactions of nigrostriate synaptic transmission, iontophoretic $o$-methylated phenethylamines, dopamine, apomorphine and acetylcholine. Brain Res. 115: 257-272. 